\title{
An investigation into martensitic transformation in hot stamping process
}

\author{
M. Naderi \& W. Bleck \\ Institute of Ferrous Metallurgy, RWTH Aachen University, Germany
}

\begin{abstract}
The main target of the hot stamping process is to get fully martensitic microstructure in the end product. In the current study, the hot stamping process is simulated by the simultaneous forming and quenching experiments. This is done through uniaxial compression tests at high temperatures by a dilatometry machine. The effects of process parameters like strain, strain rate, initial deformation temperature and austenization soaking time and mainly the applied force, on martensitic transformation of the ultra high strength boron steel are investigated. Besides, the presence of other phases like bainite and ferrite and their effects on martensitic transformation is considered. It is concluded that by increasing strain rate and initial deformation temperature, martensite content, hardness and martensite start temperature $\left(\mathrm{M}_{\mathrm{s}}\right)$ are increased. On the contrary, by applying higher deformations, the above mentioned properties are decreased. It is also concluded that, regardless of the process parameters, higher applied forces deteriorate the successful martensitic transformation during the hot stamping process.
\end{abstract}

Keywords: hot stamping, boron steel, martensitic transformation.

\section{Introduction}

In hot stamping process, the material is subjected to a high temperature austenization and subsequently formed. Then, it is cooled in the die rapidly enough to ensure the formation of martensite. In this process the material is subjected to the thermo-mechanical treatment in the austenite region. This thermo-mechanical treatment will influence the final microstructure and properties of the material. 
The martensitic transformation depends on several factors such as chemical composition, heat treatment schedules and plastic deformation. The influence of chemical composition [1], primary austenite grain size [2] and prior plastic deformation [3] on the martensitic transformation has been reported for low alloy steels.

In the current study, the influence of process parameters on martensitic transformation through simultaneous forming and cooling is studied.

\section{Experimental set up}

The studied material is hot rolled boron steel from the $27 \mathrm{MnCrB} 5$ grade in the form of plates. Table 1 exhibits chemical composition of the investigated steel.

Table 1: $\quad$ Chemical composition of the investigated steel, mass $\%$.

\begin{tabular}{|c|c|c|c|c|c|c|c|}
\hline $\mathrm{C}$ & $\mathrm{Si}$ & $\mathrm{Mn}$ & $\mathrm{P}$ & $\mathrm{S}$ & $\mathrm{Cr}$ & $\mathrm{Ti}$ & $\mathrm{B}$ \\
\hline 0.25 & 0.21 & 1.24 & 0.010 & 0.001 & 0.34 & 0.042 & 0.002 \\
\hline
\end{tabular}

The Continuous Cooling Transformation (CCT) diagram, fig. 1, has been produced by dilatometry tests, metallographic investigations and hardness measurements. The circled numbers indicate the values of final hardness in the HV10 scale. For a heating speed of $5^{\circ} \mathrm{C} / \mathrm{s}$, the eutectoid reaction temperature $\left(\mathrm{Ac}_{1}\right)$ is $730^{\circ} \mathrm{C}$ and the start temperature of austenite to primary ferrite transformation point $\left(\mathrm{Ac}_{3}\right)$ reaches $820^{\circ} \mathrm{C}$. After austenitization at $950^{\circ} \mathrm{C}$ for eight minutes followed by quenching, microstructure becomes fully martensitic. The martensite start and finish temperatures, $\mathrm{M}_{\mathrm{s}}$ and $\mathrm{M}_{\mathrm{f}}$ lie at $400^{\circ} \mathrm{C}$ and $200^{\circ} \mathrm{C}$, respectively. It can be seen that a cooling rate greater than $37^{\circ} \mathrm{C} / \mathrm{s}$ results in fully martensitic microstructure.

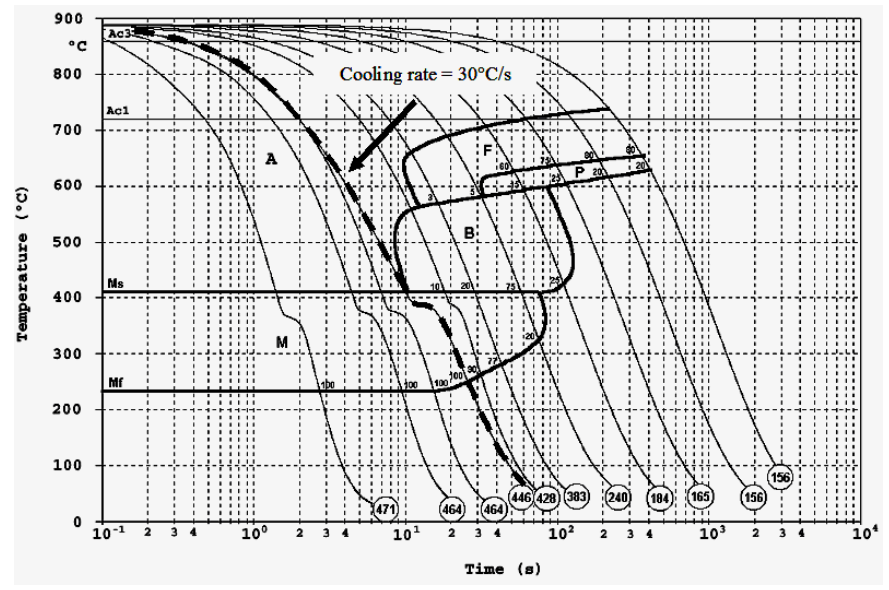

Figure 1: $\quad$ CCT Diagram of the 27MnCrB5 Boron steel. 
A Baehr DIL 805 deformation dilatometer was employed to create the thermo-mechanical schedules. Such conditions were produced by several simultaneous forming and quenching tests at temperatures between $600^{\circ} \mathrm{C}-$ $850^{\circ} \mathrm{C}$. Different strain rates between $0.1 \mathrm{~s}^{-1}-1.0 \mathrm{~s}^{-1}$ were applied. Unless otherwise, in all of the tests, samples were austenitized at $950^{\circ} \mathrm{C}$ for five minutes and quenched to compression temperature by $50^{\circ} \mathrm{C} / \mathrm{s}$. To fix the initial deformation temperature $T_{i D}$, the samples were kept for $1 \mathrm{~s}$ at the favourite $T_{i D}$ and then the deformation was carried out. The above mentioned processes as well as an example Force-Time-Temperature diagram which shows the accuracy and reproducibility of tests are illustrated in fig. 2 .
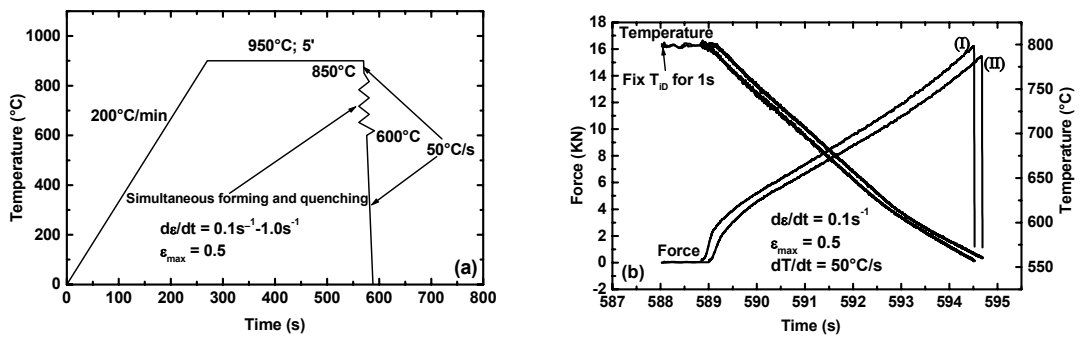

Figure 2: Simultaneous forming and quenching plan: a) the consequence of the experiment and b) an example of temperature and force evolution.

The experimental set up was as follows: inserting the cylindrical Specimen $(10 \times 5 \mathrm{~mm})$ in a vacuum chamber, resistance heating to austenization temperature and performing subsequent compression between $\mathrm{SiN}_{2}$ anvils followed by controlled cooling. Molybdenum foils were used to prevent the specimens sticking to the anvils and the glass powder was utilized for lubrication. The $\mathrm{Pt} / \mathrm{Pt}-\mathrm{Rh} 10 \%$ thermocouple was welded to the specimen in order to measure the temperature. The atmosphere was initially protected by vacuum and then argon and helium shower were employed for a controlled cooling.

\section{Results and discussions}

The martensites start $\left(\mathrm{M}_{\mathrm{s}}\right)$ and finish $\left(\mathrm{M}_{\mathrm{f}}\right)$ (or $\mathrm{M}_{\%}$ ) temperatures, martensite content, hardness and also microstructure were considered. Besides, influence of strain values, rate of deformation, austenization soaking time, magnitude of applied force and initial deformation temperature on the transformation were studied.

The effect of process parameters on critical temperatures in martensitic transformations as well as hardness and fraction of martensite in final parts are represented in fig. 3 . 

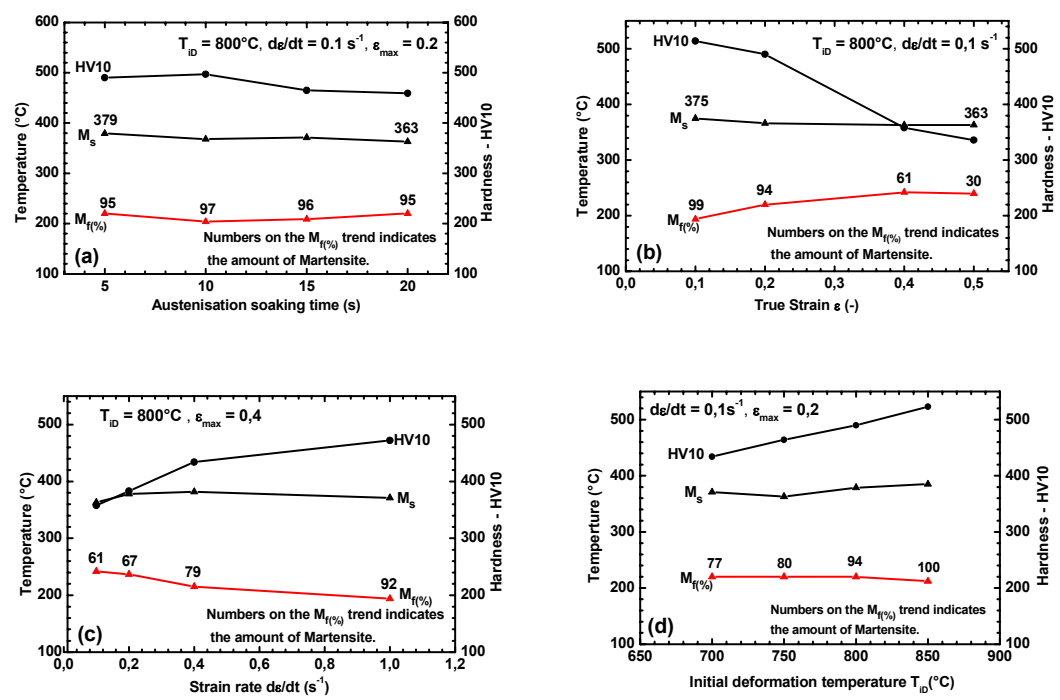

Figure 3: The effect of process parameters on the martensitic transformation; a) austenization soaking time, b) strain level, c) strain rate and d) initial deformation temperature.

It is seen that:

By increasing austenization soaking time from five to twenty minutes, the $M_{s}$ temperature decreased about $15^{\circ} \mathrm{C}$ while changes in martensite contents were negligible. Similarly, due to martensite contents, the $\mathrm{M}_{\mathrm{f}(\%)}$ temperatures are varied. It is in agreement with Unemoto [4] and Ankara's [5] observations. They described that the lath shaped martensite transformation is often associated with grain boundaries. Therefore, a nucleation argument would suggest that the finer grain sizes result in higher $\mathrm{M}_{\mathrm{s}}$ temperatures, i.e. easier nucleation since grain boundary area increases. However, the difference between the martensite contents was negligible but, due to larger martensite lath packets, hardness values decreased. It is evident that the larger austenite grain sizes resulted in coarser martensite lath packets with lower hardness levels.

During hot stamping process, the blanks are austenitized at austenite regions for a definite period of time. Concerning to the above mentioned results, the optimum austenization soaking time and temperatures must be selected to get homogenized austenite solid solution without any remaining carbides. The finer martensite lathes gives better combination of strength and formability, therefore, it is necessary to avoid coarse martensite needles formation.

In the simultaneous compression and cooling tests at constant initial deformation temperature and strain rate, larger strains will be obtained for a long time at lower temperature. It means that the possibility to have more secondary phases like ferrite and bainite owing to crossing the ferrite and bainite zones in CCT diagram is enhanced. Accordingly, martensite fractions were lowered at 
larger strains and consequently hardness values were decreased. The decrease in Ms was about $15^{\circ} \mathrm{C}$ but owing to martensite contents reduction, the $\mathrm{M}_{\mathrm{f}(\%)}$ temperature increased about $50^{\circ} \mathrm{C}$. These results are in qualitative agreement with the earlier observations that compressive stresses decrease the Ms and dilatation values [3]. In contrast, it has also been reported that both the compressive and the tensile stresses raise the $\mathrm{M}_{\mathrm{s}}$, but the effect is small [6]. The reason for the reduction of the $\mathrm{M}_{\mathrm{s}}$ might be that, as a consequence of ferrite formation, carbon becomes enriched in the remaining austenite, which therefore transforms into martensite at somewhat lower temperature. Fig. 3.b displays that at larger strains, martensite fraction is decreased and accordingly, amount of ferrite and bainite increased. Acceleration of ferrite formation and particularly the nucleation rate by plastic deformation in the non-recrystallization regime of austenite has been reported for micro-alloyed steels [7]. Lee and Choo [8] found that pancaking of the austenite by rolling at $871-843^{\circ} \mathrm{C}$ resulted in appearance of ferrite in subsequent quenching. Without rolling, the microstructures were martensitic.

With the same interpretation as above, at the same initial deformation temperature and the same strain level, the process with higher strain rate is finished in shorter time and at higher temperature. In this regard, the possibility of the formation of secondary phases is decreased. Hence, the higher strain rates yielded to higher martensite contents and evidently higher hardness levels. The $\mathrm{M}_{\mathrm{s}}$ increased about $10^{\circ} \mathrm{C}$ and due to increase of the martensite contents the $\mathrm{M}_{\mathrm{f}}$ decreased about $50^{\circ} \mathrm{C}$, fig. 3.c.

The rise of the $M_{s}$ might be due to finer austenite grain sizes which lower required activation energy for martensitic transformation and/or decrease of ferrite fraction which enrich remaining austenite. At lower rates the presence of bainite is dominant. For instance, at $0.1 \mathrm{~s}^{-1}$ microstructure comprises of bainite and martensite while at higher rates, ferrite is also formed as separated islands.

Ferrite is a very soft phase and deteriorates the strength. The deformation speed during hot stamping process must be optimized to avoid ferrite formation and also to diminish the presence of bainite.

The higher $T_{i D}$ resulted in the higher $M_{s}$ temperature. As is seen in fig. 3.d, the $\mathrm{M}_{\mathrm{s}}$ temperature decreased from $385^{\circ} \mathrm{C}$ at the $\mathrm{T}_{\mathrm{iD}}$ of $850^{\circ} \mathrm{C}$ to $365^{\circ} \mathrm{C}$ at the $\mathrm{T}_{\mathrm{iD}}$ of $700^{\circ} \mathrm{C}$. It might be due to the fact that austenite phase is strengthened during deformation at lower temperatures than at higher temperatures. Recrystallization possibility at higher deformation temperatures will impede more dislocation generation. Consequently, the higher dislocation density, the strengthen austenite matrix before transformation. So, the $\mathrm{M}_{\mathrm{s}}$ temperature was lowered by decreasing $T_{i D}$. It is also evident from the diagram that the higher $T_{i D}$ results in higher fraction of martensite and consequently higher hardness values which are aimed in hot stamping process. It means that forming must take place at a sufficiently high temperature i.e. $>800^{\circ} \mathrm{C}$ where the driving force for austenite decomposition is low. Another realistic alternative to get martensitic microstructure might be forming at low temperatures, such as $<600^{\circ} \mathrm{C}$, i.e. below the ferrite regime. In that case, ferrite formation is not happened, although some enhancement of bainite formation may take place. This may not 
be so detrimental, however, due to the notably smaller strength difference between bainite and martensite. Accordingly, the proper temperature range is quite narrow.

Concerning to the before mentioned results and discussions, it can be concluded that the deformation in austenitic region will accelerate thermally activated phase transformations and shifts the CCT diagram to the left. Despite the CCT diagram exhibits that at cooling rates higher than $37^{\circ} \mathrm{C} / \mathrm{s}$, the final microstructure would be fully martensite, but at faster cooling rates, $50^{\circ} \mathrm{C} / \mathrm{s}$, due to deformation effects, it will be hard to get full martensite microstructure.

Although, it is not so easy to distinguish between bainite and martensite in optical microscopy, but hardness measurements can be suitable method to interpret the microstructures. Ferrite is a much softer phase than martensite. It is given a value of $160 \mathrm{HV}$ for ferrite while the martensite has a hardness of $>470$ HV10. Hardness measurements in fig. 3.a-d confirmed that the microstructure formed after a high temperature plastic deformation has hardness levels between 330-530 HV10. If the hardness of bainite is about $400 \mathrm{HV} 10$, practically some of the secondary phases in addition to the ferrite might be bainite.

The other interesting phenomena to be studied are variation of the dilatation values at different forming conditions. Fig. 4 shows the effect of process parameters on the dilatation curves.
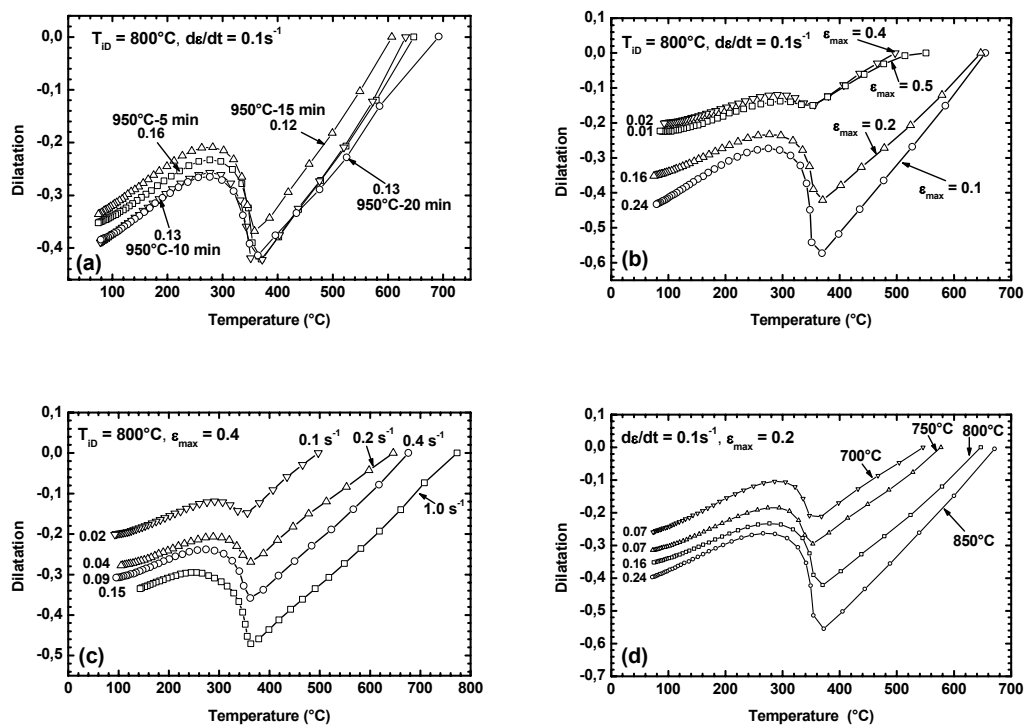

Figure 4: The effect of process parameters on the dilatation values during martensitic transformation, a) austenization soaking time, b) max. strain values, c) strain rate and d) initial deformation temperature $\mathrm{T}_{\mathrm{iD}}$. 
It must be pointed that the dilatation term is mainly the magnitude of the plastic deformation which is occurred by the martensitic transformation during cooling. This dilatation is an invariant plane strain which is the combined effect of a uniaxial dilatation and a simple shear. The higher volume fractions of martensite result in higher dilatation magnitudes. The variations of martensite contents and the $\mathrm{M}_{\mathrm{s}}$ and $\mathrm{M}_{\mathrm{f}(\%)}$ temperatures as well as the magnitude of dilatation as numbers at different conditions can be discussed by using the diagrams in fig. 4(a)-(d).

\subsection{The role of applied force}

The main process parameter in stamping process which can be controlled and monitored is applied force. The applied force in stamping process is determined by load cell on punch and therefore it can be assumed as an independent parameter.
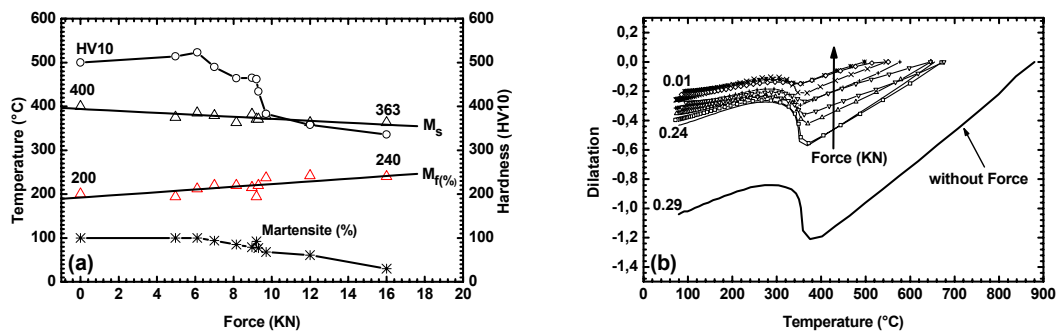

Figure 5: The effect of applied force in austenite region on martensitic transformation parameters, a) hardness, $\mathrm{M}_{\mathrm{s}}$ and $\mathrm{M}_{\mathrm{f}(\%)}$ and martensite content, b) dilatation values.

Hence, the attempts were focused on finding the relationship between applied force and martensitic transformation during simultaneous forming and quenching process. The achievements are represented in figs. 5 and 6.

It is seen that regardless of other process parameters like rate and magnitude of deformation and even $\mathrm{T}_{\mathrm{iD}}$, applied force during compression and cooling in austenite region results in:

The $\mathrm{M}_{\mathrm{s}}$ temperature decreased about $40^{\circ} \mathrm{C}$ through different applied forces between 0-16 KN while, the $\mathrm{M}_{\mathrm{f}(\%)}$ temperature were raised about $40^{\circ} \mathrm{C}$. By applying higher force levels the dislocation density of austenite matrix increases and as a consequence, more activation energy is needed to make martensitic transformation. Hence, the $\mathrm{M}_{\mathrm{s}}$ temperature is lowered.

The martensite contents and in the same manner the dilatation magnitudes-as is seen in figs. 5. $a$ and $b$ were lowered by increasing the max. applied forces. The microstructure in absence of applied force was fully martensitic whereas in the case of $16 \mathrm{KN}$ applied force, there was only about $30 \%$ martensite in microstructure. There is a minimum force limit which yielded fully martensitic microstructure and higher hardness level. As is seen in fig. 5.a, the minimum 
applied force which gave fully martensitic microstructure and higher hardness in comparison with the forceless samples was $6 \mathrm{KN}$. The hardness in the sample which tolerated $6 \mathrm{KN}$ was $523 \mathrm{HV} 10$ while in the forceless sample was $500 \mathrm{HV} 10$. It might be due to finer martensite lathes in deformed samples. It can be concluded that lower applied forces during hot stamping process result in more successful martensitic transformation and better material properties.
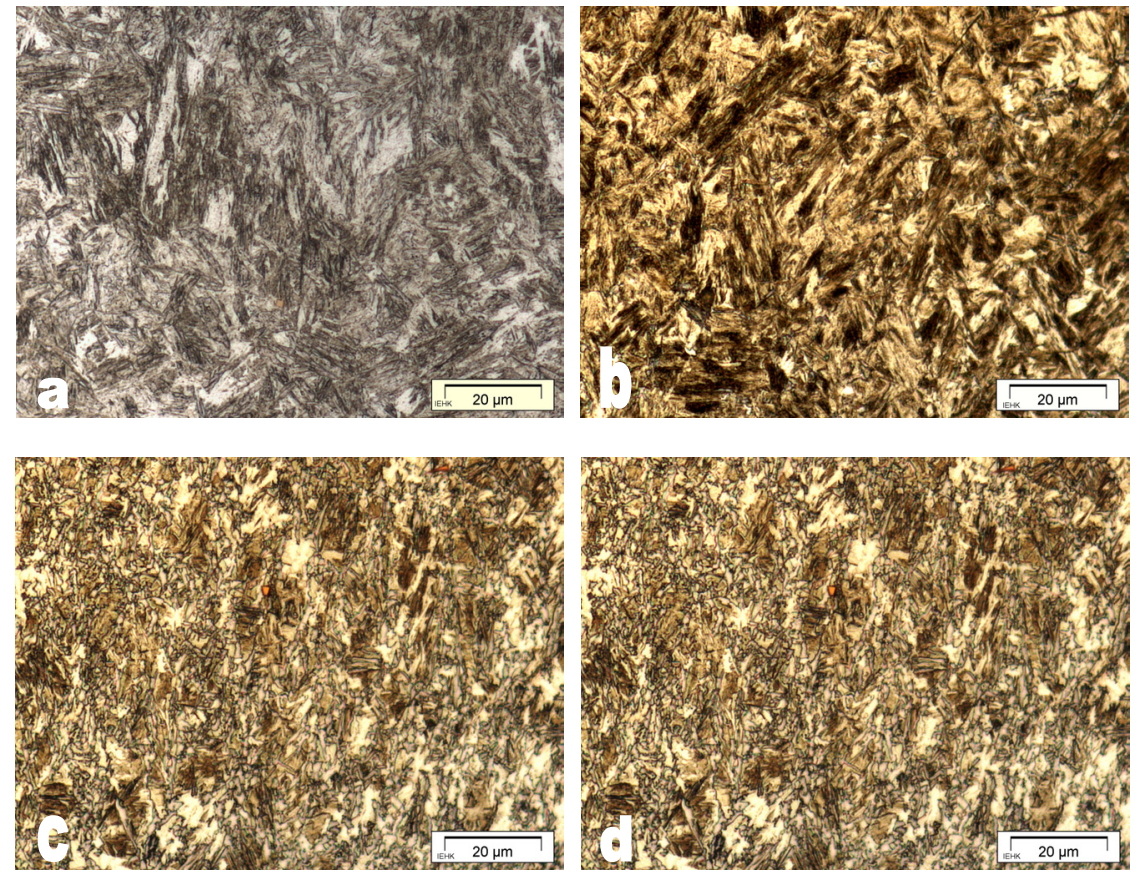

Figure 6: Microstructure evolution by applying different force levels in austenite region; a) $0 \mathrm{KN}$, b) $6.1 \mathrm{KN}$, c) $12 \mathrm{KN}$ and d) $16 \mathrm{KN}$.

As can be seen in fig. 6.a-d, the higher applied forces yielded on more bainite networks and some ferrite islands as the secondary phase. It can be concluded that by increasing the applied stress level in the austenite region, the nose of bainite in the CCT diagram not only shifts to the left but also to the lower temperatures (due to decreasing of the $\mathrm{M}_{\mathrm{s}}$ temperature).

It can be interpreted that by applying higher force levels on constant shape or volume of samples, more dislocations will be formed. Accordingly, these forests of dislocations will accelerate the thermally activated phase transformations and therefore, the nose of ferrite and bainite phases shift more and more to the left. It was also seen that the applied force in the austenite region altered the bainite nose more than ferrite zone. That is, to get fully martensitic microstructure in the final sample in hot stamping, cooling rate must be sufficiently higher than the minimum cooling rate which is mentioned in the CCT diagram, i.e. higher than $37^{\circ} \mathrm{C} / \mathrm{s}$. It can be simply concluded that to get full martensite in the end product, 
cooling rates are strongly dependent on the maximum applied force level. Instead, the higher force levels need higher cooling rates to get fully martensitic microstructure.

The above mentioned facts gives the best key points to control martensitic transformation during hot stamping process, because the applied force is the best parameter which can be in hand and in control during the process.

\section{Conclusions}

The martensitic transformation which occurs during hot stamping process was investigated by means of simultaneous hot compression and cooling in dilatometry machine, resulting in the following conclusions.

1- The $\mathrm{M}_{\mathrm{s}}$ temperature is decreased by increasing austenization soaking time. The variation of martensite content is negligible. Due to coarser martensite lathes at longer soaking time, hardness is decreased. Hence, to have a successful hot stamping process, the optimum soaking time is required to get fully fine lath martensitic microstructure.

2- At constant initial deformation temperatures $\mathrm{T}_{\mathrm{iD}}$ and constant rates, higher deformation levels are ended at lower temperatures and therefore, the possibilities to cross ferrite and bainite noses are raised. Accordingly, the martensite fractions are lowered and as a result lower hardness values are achieved. The decrease in $\mathrm{M}_{\mathrm{s}}$ is about $15^{\circ} \mathrm{C}$ but owing to martensite content reduction, the $\mathrm{M}_{\mathrm{f}(\%)}$ temperature is increased about $50^{\circ} \mathrm{C}$.

3- The higher rates of stamping, the higher temperatures to finish the deformation. At constant deformation magnitudes and constant initial deformation temperatures, higher strain rates results in more martensite fractions and higher hardness. The possibility of the presence of ferrite islands is increased by increasing the rates of deformation.

4- The higher initial deformation temperatures results in higher volume fraction of martensite which is favorite in hot stamping process. It means the time to transfer material from furnace to press must be as short as possible. The $850^{\circ} \mathrm{C}$ $800^{\circ} \mathrm{C}$ ranges is recommended as the best start temperature to deform the studied steel through hot stamping process.

5- Regardless of rate, magnitude and start temperature of deformation, maximum applied force as an outstanding parameter in hot stamping process can give the best interpretations. The higher forces are applied in austenite region, the martensite volume fractions and the hardness levels are decreased. The $M_{s}$ temperature is decreased about $40^{\circ} \mathrm{C}$ by applying $16 \mathrm{KN}$ force to compression samples. In hot stamping process, the lowest possible level of force must be applied to achieve the favorite microstructure.

6- It can be concluded that by applying deformation in austenite region the CCT diagram shifts not only to the left but also to the lower temperatures. Accordingly, the criteria to get full martensitic microstructure in final product through hot stamping process do not follow the CCT boundary conditions and must be cared. Instead, the higher applied force, the faster cooling rate to get fully fine lath martensitic microstructure. 


\section{References}

[1] C. Capdevila, F.G. Caballero and C. Garcia de Andres, Analysis of the effect of alloying elements on the martensite-start temperature of the steels, Materials science and Technology, 2003, Vol.15, no.5, 581-586.

[2] P.J. Brofman, G.S. Ansell, The Effect of Fine Grain Size on the Ms Temperature in Fe-27Ni-0.025C Alloys, Metal. Trans. A, 1983, 14A, 1929-1931.

[3] M.C. Somani, L.P. Karjalainen and M. Eriksson, Dimensional changes and microstructural evolution in a B-bearing steel in the simulated forming and quenching process, ISIJ International, Vol. 41, No.4, 2001, 361-367.

[4] M. Unemoto, W.S. Owen, Effects of austenitizing temperature and austenite grain size on the formation of athermal martensite in an ironnickel and an iron-nickel-carbon alloy, Metal. Trans., 1975, 5, 2041-2053.

[5] O.A. Ankara, A.S. Sastri, D.R.F. West, Some effects of austenitizing conditions on martensite formation in an iron-20\% nickel alloy, J. Iron and steel institute, 1966, 509-511.

[6] S. Denis, E. Gautier, A. Simon, and G. Beck, Stress-phase-transformation interactions-basic principles, modelling and calculation of internal stresses, Mater.Sci.Technol. 1, 1985, 805-814.

[7] I. Tamura, C. Ouchi, and T. Tanaka, Thermo-mechanical processing of high strength low alloy steels, Butterworth, London, 1988, 99.

[8] C.S. Lee, and W.Y. Choo, Effects of austenite conditioning and hardenability on mechanical properties of B-containing high strength steel, ISIJ Int. 40, 2000, S189-S193. 